\title{
DISPERSÃO ANEMÓFILA DE ESPORANGIÓSPOROS DE Plasmopara viticola EM CULTIVOS PROTEGIDO E CONVENCIONAL DE VIDEIRA ${ }^{1}$
}

\author{
GERALDO CHAVARRIA ${ }^{2}$, HENRIQUE PESSOA DOS SANTOS 3 , EMANUELA FIN ${ }^{4}$, \\ OLAVO ROBERTO SÔNEGO ${ }^{5}$, LUCAS DA RESSURREIÇÃO GARRIDO ${ }^{6}$, \\ GILMAR ARDUÍNO BETTIO MARODIN ${ }^{7}$
}

\begin{abstract}
RESUMO - No presente trabalho, foram avaliadas as taxas de dispersão anemófila de esporangiósporos de Plasmopara viticola nos ciclos de 2005/06 e 2006/07 e sua correlação com o microclima, em vinhedo sob cobertura plástica e em cultivo convencional. Foi utilizado vinhedo comercial da cultivar Moscato Giallo (Vitis vinifera L.), localizado em Flores da Cunha-RS $\left(29^{\circ} 06^{\prime} \mathrm{S}, 51^{\circ} 20^{\prime} \mathrm{O}, 541 \mathrm{~m}\right)$. Este foi coberto com plástico impermeável tipo ráfia $(160 \mu \mathrm{m})$, de 12 fileiras com $35 \mathrm{~m}$, deixando-se cinco fileiras sem cobertura (controle). O microclima do vinhedo foi avaliado próximo ao dossel vegetativo, em ambos tratamentos, considerando: temperatura, umidade relativa, velocidade do vento e precipitação pluvial. A presença de esporos em cada área foi determinada por coletores de esporos, utilizando fitas transparentes, untadas com solução adesiva de gelvatol. Semanalmente, as fitas foram retiradas das armadilhas e postas em lâminas de microscopia, das quais, em cada ciclo, foram selecionadas 20, dias de cada sistema de cultivo e analisado com auxílio de microscópio. O vinhedo sob cobertura plástica apresentou maior quantidade de dispersão anemófila de esporangiósporos de Plasmopara viticola. Maiores dispersões anemófilas destes esporangiósporos foram observadas no período da tarde, independentemente do sistema de cultivo.
\end{abstract}

Termos para indexação: plasticultura, Vitis vinifera, manejo fitossanitário, doenças fúngicas, míldio.

\section{AERIAL DISPERSION OF Plasmopara viticola SPORES IN COVERED AND CONVENTIONAL CULTIVATION OF GRAPEVINE}

\begin{abstract}
In the present study it was evaluated the aerial dispersion rate of Plasmopara viticola spores during 2005/06 and 2006/07 seasons and their relation with microclimate under covered and conventional cultivation of grapevine. A commercial vineyard of Moscato Giallo cultivar (Vitis vinifera L.) in Flores da Cunha, RS (29 $\left.06^{\circ} \mathrm{S}, 51^{\circ} 20^{\prime} \mathrm{W}, 541 \mathrm{~m}\right)$ was used. It comprised twelve rows of plants covered with a transparent plastic (raffia type $-160 \mu \mathrm{m}$ ) and five uncovered rows of plants, each row with $35 \mathrm{~m}$ of length. The microclimate was evaluated, in terms of air temperature, air relative humidity, wind speed and pluvial precipitation above the canopy in both treatments. Two spore traps were installed in each treatment by using transparent tapes with gelvatol. Every week, the tapes were retrieved and mounted on slides for microscopy, randomly selected 20 days in each treatment and season, where the number of trapped spores was determined. The covered vineyard showed the highest amount of aerial dispersion of spores Plasmopara viticola. Regardless of the cultivation in the afternoon period, it was observed higher dispersion.

Index Terms: plasticulture, Vitis vinifera, disease management, fungal diseases, mildium.
\end{abstract}

\footnotetext{
(Trabalho 220-08). Recebido em: 27-08-2008. Aceito em: 04-05-2009.

${ }^{2}$ Eng. Agr ${ }^{\circ}$ Dr. Prof. Fisiologia das Plantas Cultivadas, Universidade de Passo Fundo, Passo Fundo-RS. e-mail: geraldochavarria@upf.br ${ }^{3}$ Eng. Agr ${ }^{\circ}$ Dr. Pesquisador Embrapa Uva e Vinho, Bento Gonçalves-RS., e-mail: henrique@cnpuv.embrapa.br ${ }^{4}$ Graduanda Engenharia de Bioprocessos Universidade Estadual do Rio Grande do Sul - UERGS

${ }^{5}$ Eng. Agr ${ }^{\circ}$ M. Sc. Pesquisador Embrapa Uva e Vinho, Bento Gonçalves-RS., e-mail: sonego@cnpuv.embrapa.br

${ }^{6}$ Eng. Agr ${ }^{\circ}$ Dr. Pesquisador Embrapa Uva e Vinho, Bento Gonçalves-RS., e-mail: lucas@cnpuv.embrapa.br

${ }^{7}$ Eng. Agr ${ }^{\circ}$ Prof. Dr. Depto. de Horticultura, Universidade Federal do Rio Grande do Sul, Porto Alegre-RS. e-mail: marodin@ufrgs.br
} 


\section{INTRODUÇÃO}

O pseudofungo Plasmopara viticola (Berk. \& Curt) Berl. \& De Toni, antes pertencente à Classe Oomicetos, é atualmente reenquadrado no Reino Stramenopila e é o agente causal do míldio-da-videira (Alexopoulos et al., 1996). Esta doença é considerada de grande importância econômica em virtude dos danos provocados, caso medidas adequadas de controle não sejam tomadas (Amorin \& Kuniyuki, 2005). No cultivo convencional a céu aberto de uvas Vitis vinifera, no Rio Grande do Sul, são realizadas em média 14 pulverizações com fungicidas, consistindo em aproximadamente $30 \%$ do custo de produção (Freire et al., 1992). Destas aplicações, 8 a 10 são efetuadas para o controle do míldio-davideira (Mendes, 2002). Existem regiões do Brasil, como no Estado do Paraná, onde são realizadas até 60 pulverizações em uvas Vitis vinifera. De forma corrente, o produtor realiza pulverizações semanais (método por calendário), com a intenção de garantir a produção, sendo que, em determinadas situações, pode não existir a real necessidade de aplicação de fungicidas, decorrente de condições climáticas adversas para o desenvolvimento da doença.

O cultivo de videiras sob cobertura plástica, em regiões que apresentam excesso de chuvas no período da maturação, como no caso da "Serra Gaúcha", pode ser uma alternativa viável na obtenção de uvas sadias (Chavarria et al., 2007a) e, dependendo do manejo que é dado, pode ser obtida a produção orgânica (Chavarria et al., 2007b). Isto porque a cobertura restringe a água livre sobre folhas e frutos, que é o principal fator para desencadear o início das infecções fúngicas na videira (Grigoletti Júnior \& Sônego, 1993).

Atualmente, não existem estudos que descrevam o comportamento da dispersão anemófila de esporangiósporos de Plasmopara viticola sob cultivo protegido da videira. Considerando que este tipo de cultivo afeta os elementos microclimáticos e a aplicação de fungicidas (Chavarria et al., 2007a), existe a hipótese de que seja alterada a quantidade e/ ou a mobilidade de esporos nestas condições.

O detalhamento da dispersão anemófila de esporos contitui-se em uma informação de relevância no avanço do manejo fitossanitário (Casa et al., 2004; Correia \& Costa, 2005). Haja vista que o conhecimento epidemiológico das doenças, permite a criação de modelos capazes de realizar previsões aumentando a eficácia do controle fitossanitário (Sutton, 1998).

De acordo com o abordado, o objetivo do presente trabalho foi avaliar a dispersão anemófila de esporangiósporos de Plasmopara viticola em cultivo protegido e convencional nos ciclos de 2005/06 e 2006/07 da cultivar Moscato Giallo, no município de Flores da Cunha, na "Serra Gaúcha".

\section{MATERIAL E MÉTODOS}

O experimento foi conduzido nos ciclos de 2005/06 e 2006/07 em vinhedo comercial localizado em Flores da Cunha - RS, distrito de Mato Perso (latitude $29^{\circ} 06^{\prime} \mathrm{S}$, longitude $51^{\circ} 20^{\prime} \mathrm{O}$ e altitude $541 \mathrm{~m}$ ), da cultivar 'Moscato Giallo' (clone VCR1), enxertada em porta-enxerto 'Kober 5BB' e com espaçamento de 3,0 x 0,9 m (3703 plantas.ha-1 $)$.

As plantas estavam conduzidas em "Y", com fileiras de 35 metros na direção nordeste-sudoeste, com poda mista, deixando varas de 6 a 8 gemas e esporões de duas gemas. $\mathrm{O}$ vinhedo foi dividido em duas partes. A primeira parte foi constituída por 12 fileiras cobertas na linha de cultivo com lonas plásticas trançadas de polipropileno transparentes, impermeabilizadas com polietileno de baixa densidade, com $160 \mu \mathrm{m}$ de espessura e largura de 2,65 m. Na segunda parte, mantiveram-se cinco fileiras descobertas, cujas linhas centrais foram consideradas como plantas-controle.

Para realizar o monitoramento dos esporangiósporos do fungo Plasmopara viticola foram utilizadas duas armadilhas volumétricas (Burkard Scientific Intruments, Rickmansworth, Herts, U.K.), sendo uma delas posicionada na área sob cobertura plástica, e outra na área de cultivo convencional. Estas armadilhas possuem em seu interior uma bomba de vácuo que succiona o ar através de um orifício. A amostra de partículas de ar foi então depositada em uma fita transparente Melinex ${ }^{\circledR}$ montada sobre um cilíndro equipado com um relógio de corda que completa uma volta no período de uma semana (2 $\left.\mathrm{mm} \cdot \mathrm{h}^{-1}\right)$. A fita foi untada com uma camada de solução de Gelvatol. Semanalmente, a fita foi retirada do aparelho e segmentada sete vezes em pedaços de $48 \mathrm{~mm}$, equivalentes a um intervalo diário. Estes segmentos foram colocados sobre lâminas de microscopia e marcados em 24 espaços de $2 \mathrm{~mm}$, o que representava intervalos horários. Do período do mês de outubro a abril, foram selecionados aleatoriamente 20 dias, onde, por meio do auxílio de microscópio óptico (400X), foi realizada a contagem de esporangiósporos de $P$. viticola capturados a cada hora nas áreas coberta e descoberta. Estes procedimentos foram realizados no Laboratório de Fitopatologia da Embrapa Uva e Vinho.

O microclima foi avaliado nas áreas com e sem cobertura plástica, na altura do dossel vegetativo. 
Constou de medições de temperatura $(\mathrm{T})$ e umidade relativa do ar (UR) - (psicrômetros de pares termoelétricos); velocidade do vento $(\mathrm{V})$ - (anemômetro de conchas). Todos os sensores da área experimental foram conectados a sistemas de aquisição de dados (CR10 e CR21X, Campbell ${ }^{\circledR}$ ). Ambos os sistemas foram programados para efetuar leituras a cada minuto e médias a cada 30 minutos. Em frente ao vinhedo avaliado, foi instalada uma estação meteorológica automática Campbell ${ }^{\circledR}$, onde foram obtidos dados de precipitação pluvial.

$\mathrm{Na}$ análise estatística dos parâmetros micrometeorológicos, utilizou-se o programa $\mathrm{R}$ ( $\mathrm{R}$, 2007), sendo que os mesmos (temperatura média, mínima e máxima; umidade relativa; radiação fotossinteticamente ativa e velocidade do vento) foram pareados, e as diferenças entre ambos tratamentos foram analisadas por regressão linear em função da área descoberta. A significância do coeficiente angular das equações resultantes foi avaliada pelo Teste t. $\mathrm{Na}$ análise dos dados de radiação fotossinteticamente ativa e velocidade do vento, o intercepto foi fixado em zero, pois quando a medida externa for nula, a interna deve também ser obrigatoriamente nula.

Os dados de dispersão anemófila de esporangiósporos de $P$. viticola das áreas coberta e descoberta foram transformados em $\sqrt{x+1} \mathrm{e}$ submetidos à análise de variância (ANOVA), e as médias, comparadas pelo teste de Tukey, a 5\% de probabilidade de erro.

Os dados de dispersão de esporangiósporos e microclima foram pareados e estabelecidos coeficientes de correlação.

Ao longo de todo o ciclo vegetativo/produtivo também foi registrado o número de aplicações de fungicidas nas áreas coberta e descoberta, assim como os produtos utilizados, objetivando caracterizar os contrastes na necessidade de controle fitossanitário (Tabela 1).

\section{RESULTADOS E DISCUSSÃO}

A quantidade média diária de esporangiósporos de $P$. viticola capturado na área sob cobertura plástica foi significativamente superior à média diária do cultivo convencional (Tabela 2). Embora não tenha sido verificada diferença significativa para as médias entre os tratamentos, nos ciclos de 2005/06 e 2006/07, pôde ser observada uma tendência considerável de a área coberta apresentar maiores valores. Contudo, levando em consideração a média horária, a área coberta apresentou quantidades significativamente superiores de esporangiósporos em relação à area descoberta, nos ciclos de 2005/06 e 2006/07 (Tabela
2).

Considerando a dispersão ao longo do dia, de acordo com a Figura 1, pode ser observado que, em todas as avaliações, a área coberta apresentou tendência à maior presença de esporos, embora na avaliação total entre os dois sistemas de cultivo tenham sido observadas diferenças significativas somente nos horários das $00 ; 01 ; 10 ; 11 ; 12 ; 15$; $16 ; 18$ e 23 h. No ciclo de 2005/06, não foram observadas diferenças significativas entre as áreas coberta e descoberta. Entretanto, os valores médios de dispersão de esporos foram sempre superiores na área coberta. Contudo, no ciclo de 2006/07, foi observado que a quantidade de esporos da área coberta foi significativamente superior às $00 ; 11$; 12; 15 e 18 h (Figura 1C). Também foi constatado que a maior captura de esporos ocorreu no período diurno da tarde, sobretudo no horário das 9 às $20 \mathrm{~h}$ (Figuras 1A, 1B e 1C).

A presença dos esporos na área coberta, supostamente, ocorre pela vinda das áreas adjacentes com cultivo convencional. Isto porque, na região, existe grande quantidade de vinhedos, e a produção de inóculo foi pequena no cultivo protegido, em função da ausência da doença (Chavarria et al., 2007a). Ressalta-se que o principal mecanismo de sobrevivência do $P$. viticola é por meio de oósporos presentes no interior de tecidos de folhas senescidas sobre o solo e micélios dormentes em gemas (Mendes, 2002), e para que ocorra a germinação destes oósporos, é necessário temperatura acima de $10^{\circ} \mathrm{C}$ durante uma precipitação superior a $10 \mathrm{~mm}$ (ausente nas videiras sob cobertura plástica). Os esporangiósporos e os zoósporos são transportados pelo vento, gotas de chuva, assim como outros agentes mecânicos, para os tecidos da videira (Spencer, 1981; Rosa et al., 1993). Mesmo que os oósporos tenham produzido esporangiósporos (inóculo primário), estes não originaram infecções nos tecidos da planta da área coberta e, consequentemente, não houve infecções secundárias com a produção de novos esporangiósporos.

Outro fator que pode ter influenciado para a maior detecção de esporangiospóros de $P$. viticola, na área coberta, pode ser a falta de fixação dos mesmos às folhas, devido à ausência de filme de água necessário para as infecções causadas pelos zoósporos (Dean, 1992).

No ciclo de 2005/06, foram realizadas 17 aplicações no cultivo convencional, visando ao controle do míldio, e duas na área coberta, para o controle do oídio, enquanto no ciclo de 2006/07 foram realizadas 15 aplicações no convencional e nenhuma aplicação de fungicidas na área coberta 
(Tabela 1). A ausência de fungicida, com efeito sobre o míldio, no cultivo sob cobertura plástica, nos dois ciclos, pode ter favorecido a proliferação de esporos que foi observada (Figura 1). Sabe-se, porém, que a maioria dos fungicidas utilizados no controle do míldio da videira afetam a esporulação e a germinação dos esporos (Wong \& Wilcox, 2001).

Em avaliações do efeito da cobertura plástica sobre a incidência de doenças fúngicas, aplicação de fungicidas e sua persistência residual em videiras, Chavarria et al. (2007a) observaram diminuição considerável do número de aplicações de fungicidas, sendo que foram realizadas apenas duas aplicações para o controle do oídio na área coberta, enquanto na área descoberta foram realizadas 17 aplicações para o controle geral de doenças fúngicas. Em relação à incidência de doenças, os autores destacaram que as condições microclimáticas propiciadas pela cobertura plástica não permitiram o estabelecimento de míldio e produziram decréscimos significativos na incidência de podridão ácida $(-77,10 \%)$ e na severidade de podridão-da-uva-madura $(-89,47 \%)$, podridão-cinzenta-da-uva $(-57,56 \%)$ e podridão ácida $(-84,54 \%)$ em função da cobertura plástica.

Segundo Mendes (2002), que avaliou a dispersão anemófila de esporangiósporos de $P$. viticola em vinhedo da cultivar Isabel, em cultivo convencional, na região vitivinícola da "Serra Gaúcha", o inóculo está presente ao longo de todo o ano, estando somente dependente de condições favoráveis para ocorrência da doença.

Associado ao fato de que a cobertura plástica evita a incidência de míldio-da-videira (Chavarria et al., 2007a), a presença de esporos ao longo de todo o ano (Mendes, 2002) e a maior presença de esporos encontrados na área coberta no presente estudo, existe a possibilidade de que o fator que impede a proliferação da doença em questão, sejam as condições microclimáticas desfavoráveis, sobretudo a diminuição da água livre sobre folhas e cachos.

Nas avaliações das condições microclimáticas realizadas nos dois ciclos (2005/06 e 2006/07), foram observadas alterações ocasionadas pelo uso da cobertura plástica sobre as fileiras de cultivo (Tabela 3). Com relação à temperatura, as máximas diárias foram as que mais sofreram influência. À medida que a temperatura máxima diminui fora da cobertura, a redução correspondente sob a cobertura é menor. Isso pode ser verificado pelo coeficiente de regressão significativo $\left(\mathrm{r}^{2}=0,74 ; \mathrm{P}=0,0005\right)$, que indica que, para cada ${ }^{\circ} \mathrm{C}$ de redução na temperatura externa, a temperatura abaixo da cobertura cai $0,90^{\circ} \mathrm{C}$. Em função desse efeito, a temperatura média teve um efeito similar, porém com menor coeficiente de regressão $\left(\mathrm{r}^{2}=0,95 ; \mathrm{P}=0,0265\right)$, indicando uma queda de $0,96^{\circ} \mathrm{C}$ sob a cobertura para cada ${ }^{\circ} \mathrm{C}$ de variação na temperatura externa. Esse efeito foi ainda menor nas temperaturas mínimas diárias $\left(\mathrm{r}^{2}=0,94 ; \mathrm{P}=0,0012\right)$ (Tabela 3). O aumento das temperaturas máximas foi observado também por Ferreira et al. (2004), analisando vinhedo de 'Cabernet Sauvignon' com cobertura plástica nas linhas de cultivo. A temperatura apresentou correlação negativa $(\mathrm{P}<0,001)$ com a dispersão de esporos nas áreas coberta e descoberta, no ciclo de 2006/07; todavia, o ciclo anterior não apresentou coeficiente de correlação significativo (Tabela 4).

A velocidade do vento foi atenuada em 90,4\% junto ao dossel vegetativo das plantas cultivadas sob cobertura plástica (Tabela 3). Além da influência sobre a temperatura, a redução da velocidade do vento pode interferir, de maneira positiva, sobre a diminuição de incidência e severidade de doenças, pois o vento e a chuva são os principais fatores de dispersão de esporos de fungos (Aita, 1983). A velocidade do vento apresentou os maiores coeficientes de correlação com a dispersão de esporos, indicando a influência deste fator sobre o fenômeno (Tabela 4).

Apesar dessas alterações de temperatura e velocidade do vento, observou-se que a umidade relativa foi o parâmetro que teve menor variação em relação ao ambiente externo, sendo que, para cada unidade percentual (u.p.) de variação externa, houve 0,85 u.p $\left(\mathrm{r}^{2}=0,91 ; \mathrm{P}<0,0001\right)$ (Tabela 3). Somente foi observada correlação entre umidade relativa e quantidade de esporos, quando considerados os dois sistemas (Tabela 4). Entretanto, observou-se, ao longo do experimento, que a água livre sobre folhas e frutos foi nula na área coberta. Sabe-se que esta, estando disponível, atua em vários processos relacionados às infecções das doenças, incluindo a liberação e a germinação de esporos, penetração do tubo germinativo de fungos e a multiplicação de células de fitobactérias, os quais ficam apenas dependentes da temperatura para seu estabelecimento (Agrios, 1997). Portanto, o efeito mais benéfico do cultivo protegido no controle fitossanitário das videiras pode ser considerado a isenção de água livre no sistema. 
TABELA 1 - Fungicidas utilizados no controle de doenças fúngicas em vinhedo da cultivar Moscato Giallo conduzida em "Y", com (coberto) e sem (descoberto) cobertura plástica nos ciclos de 2005/06 e 2006/07. Flores da Cunha-RS.

\begin{tabular}{|c|c|c|c|c|c|}
\hline \multicolumn{6}{|c|}{ Ciclo 2005/06 } \\
\hline \multicolumn{3}{|c|}{ Coberto } & \multicolumn{3}{|c|}{ Descoberto } \\
\hline Produto & Dosagem & Mistura & Produto & Dosagem & Mistura \\
\hline Rubigan & $15 \mathrm{~mL} .100 \mathrm{~L}^{-1}$ & - & Manzate & $3 \mathrm{~kg} \cdot \mathrm{ha}^{-1}$ & Delan $0,5 \mathrm{~kg} \cdot \mathrm{ha}^{-1}$ \\
\hline Folicur & $200 \mathrm{~mL} .100 \mathrm{~L}^{-1}$ & - & Manzate & $3 \mathrm{~kg} \cdot \mathrm{ha}^{-1}$ & Delan $0,5 \mathrm{~kg} \cdot \mathrm{ha}^{-1}$ \\
\hline- & - & - & Manzate & $3 \mathrm{~kg} \cdot \mathrm{ha}^{-1}$ & Delan $0,5 \mathrm{~kg} \cdot \mathrm{ha}^{-1}$ \\
\hline- & - & - & Manzate & $3 \mathrm{~kg} \cdot \mathrm{ha}^{-1}$ & Curzate $2 \mathrm{~kg} \cdot \mathrm{ha}^{-1}$ \\
\hline- & - & - & Manzate & $3 \mathrm{~kg} \cdot \mathrm{ha}^{-1}$ & Curzate $2 \mathrm{~kg} \cdot \mathrm{ha}^{-1}$ \\
\hline- & - & - & Manzate & $3 \mathrm{~kg} \cdot \mathrm{ha}^{-1}$ & Curzate $2 \mathrm{~kg} \cdot \mathrm{ha}^{-1}$ \\
\hline- & - & - & Cabrio Top & 2,5 kg.ha-1 & - \\
\hline- & - & - & Curzate & $3 \mathrm{~kg} \cdot \mathrm{ha}^{-1}$ & Fitofós 1L.ha' ${ }^{-1}$ \\
\hline- & - & - & Cabrio Top & 2,5 kg.ha' & - \\
\hline- & - & - & Curzate & $3 \mathrm{~kg} \cdot \mathrm{ha}^{-1}$ & Fitofós 1L.ha' ${ }^{-1}$ \\
\hline- & - & - & Cabrio Top & 2,5 kg.ha' & - \\
\hline- & - & - & Curzate & $3 \mathrm{~kg} \cdot \mathrm{ha}^{-1}$ & Fitofós 1L.ha ${ }^{-1}$ \\
\hline- & - & - & Cabrio Top & 2,5 kg.ha' & - \\
\hline - & - & - & Cuprazol & 2L.ha' ${ }^{-1}$ & - \\
\hline- & - & - & Cuprazol & 2L.ha $a^{-1}$ & - \\
\hline- & - & - & Cuprazol & 2L.ha ${ }^{-1}$ & - \\
\hline- & - & - & Cuprazol & 2L.ha' ${ }^{-1}$ & - \\
\hline - & - & - & Cuprazol & 2L.ha' ${ }^{-1}$ & - \\
\hline
\end{tabular}

Ciclo 2006/07

\begin{tabular}{|c|c|c|c|c|c|}
\hline \multicolumn{3}{|c|}{ Coberto } & \multicolumn{3}{|c|}{ Descoberto } \\
\hline Produto & Dosagem & Mistura & Produto & Dosagem & Mistura \\
\hline- & - & - & Manzate & $3 \mathrm{~kg} \cdot \mathrm{ha}^{-1}$ & Delan $0,5 \mathrm{~kg} \cdot \mathrm{ha}^{-1}$ \\
\hline- & - & - & Manzate & $4 \mathrm{~kg} \cdot \mathrm{ha}^{-1}$ & Delan $0,5 \mathrm{~kg} \cdot \mathrm{ha}^{-1}$ \\
\hline- & - & - & Manzate & $3 \mathrm{~kg} \cdot \mathrm{ha}^{-1}$ & Delan $0,5 \mathrm{~kg} \cdot \mathrm{ha}^{-1}$ \\
\hline- & - & - & Manzate & $3 \mathrm{~kg} \cdot \mathrm{ha}^{-1}$ & Delan $0,5 \mathrm{~kg} \cdot \mathrm{ha}^{-1}$ \\
\hline- & - & - & Manzate & $2 \mathrm{~kg} \cdot \mathrm{ha}^{-1}$ & Delan $0,5 \mathrm{~kg} \cdot \mathrm{ha}^{-1}$ \\
\hline- & - & - & Curzate & $2,5 \mathrm{~kg} \cdot \mathrm{h}^{-1}$ & Fitofós $1 \mathrm{~L} \cdot \mathrm{ha}^{-1}$ \\
\hline- & - & - & Curzate & $2,5 \mathrm{~kg} \cdot \mathrm{ha}^{-1}$ & Fitofós $1 \mathrm{~L} \cdot \mathrm{ha}^{-1}$ \\
\hline- & - & - & Cabrio Top & $2 \mathrm{~kg} \cdot \mathrm{ha}^{-1}$ & Delan $0,5 \mathrm{~kg} \cdot \mathrm{ha}^{-1}$ \\
\hline- & - & - & Curzate & $2,5 \mathrm{~kg} \cdot \mathrm{ha}^{-1}$ & Fitofós 1L.ha-1 \\
\hline- & - & - & Cabrio Top & $2,5 \mathrm{~kg} \cdot \mathrm{ha}^{-1}$ & - \\
\hline- & - & - & Curzate & $2,5 \mathrm{~kg} \cdot \mathrm{ha}^{-1}$ & - \\
\hline- & - & - & Curzate & $2,5 \mathrm{~kg} \cdot \mathrm{ha}^{-1}$ & - \\
\hline- & - & - & $\begin{array}{l}\text { Sulfato de } \\
\text { çobre }\end{array}$ & 1kg.ha-1 & - \\
\hline- & - & - & $\begin{array}{l}\text { Sulfato de } \\
\text { cobre }\end{array}$ & $1 \mathrm{~kg} \cdot \mathrm{ha}^{-1}$ & - \\
\hline- & - & - & $\begin{array}{c}\text { Sulfato de } \\
\text { cobre }\end{array}$ & $1 \mathrm{~kg} \cdot \mathrm{ha}^{-1}$ & - \\
\hline
\end{tabular}


TABELA 2 -Médias diária e horária de dispersão de esporangiósporos de Plasmopara viticola em cultivo de videira (Vitis vinifera L.) cv. Moscato Giallo, com (coberto) e sem (descoberto) cobertura plástica, nos ciclos de 2005/06 e 2006/07. Flores da Cunha-RS.

\begin{tabular}{|c|c|c|c|c|c|c|}
\hline \multirow{2}{*}{ Tratamento } & \multicolumn{3}{|c|}{ Média.dia $^{-1}$} & \multicolumn{3}{|c|}{ Média.hora $^{-1}$} \\
\hline & $2005 / 06$ & $2006 / 07$ & Média & $2005 / 06$ & 2006/07 & Média \\
\hline Coberto & $687,65 \mathrm{aA}^{*}$ & $980,9 \mathrm{aA}$ & $834,28 \mathrm{a}$ & $28,65 \mathrm{aB}$ & $40,87 \mathrm{aA}$ & $34,76 \mathrm{a}$ \\
\hline Descoberto & $404,15 \mathrm{aA}$ & $490,05 \mathrm{aA}$ & $447,1 b$ & $16,84 \mathrm{bA}$ & $20,42 \mathrm{bA}$ & $18,63 b$ \\
\hline CV (\%) & \multicolumn{2}{|c|}{125,38} & \multicolumn{4}{|c|}{176,56} \\
\hline
\end{tabular}

*Médias seguidas de letras minúsculas (entre tratamentos no mesmo ciclo) e maiúsculas (entre ciclos no mesmo tratamento) distintas diferem entre si, ao nível de significância de 5\%, de acordo com teste de Tukey.

TABELA 3 - Médias das observações microclimáticas em vinhedo da cultivar Moscato Giallo conduzida em "Y", com (C) e sem (D) cobertura plástica, nos ciclos de 2005/06 e 2006/07. Flores da Cunha-RS.

\begin{tabular}{|c|c|c|c|c|c|}
\hline \multirow{2}{*}{ Variáveis microclimáticas } & \multicolumn{2}{|c|}{$2005 / 2006$} & \multicolumn{2}{|c|}{$2006 / 2007$} & \multirow{2}{*}{ Equações de regressão } \\
\hline & $\mathrm{C}$ & $\mathrm{D}$ & $\mathrm{C}$ & $\mathrm{D}$ & \\
\hline Tmáx. dossel $\left({ }^{\circ} \mathrm{C}\right)$ & 31,94 & 28,19 & 30,37 & 31,18 & $\begin{array}{l}\mathrm{C}=4,51+0,897 \mathrm{D}(\mathrm{P}=0,0005)^{* *} \\
\mathrm{R}^{2}=0,74\end{array}$ \\
\hline Tmédia dossel $\left({ }^{\circ} \mathrm{C}\right)$ & 21,28 & 20,28 & 21,91 & 21,84 & $\begin{array}{l}\mathrm{C}=1,37+0,960 \mathrm{D}(\mathrm{P}=0,0265) \\
\mathrm{R}^{2}=0,95\end{array}$ \\
\hline Tmín. dossel $\left({ }^{\circ} \mathrm{C}\right)$ & 14,62 & 14,45 & 16,33 & 16,07 & $\begin{array}{l}\mathrm{C}=0,64+0,972 \mathrm{D}(\mathrm{P}=0,0012) \\
\mathrm{R}^{2}=0,94\end{array}$ \\
\hline Umidade relativa dossel (\%) & 83,12 & 82,51 & $*$ & $*$ & $\begin{array}{l}\mathrm{C}=13,2+0,848 \mathrm{D}(\mathrm{P}<0,0001) \\
\mathrm{R}^{2}=0,89\end{array}$ \\
\hline Velocidade do vento diária $\left(\mathrm{m} . \mathrm{s}^{-1}\right)$ & 0,093 & 0,904 & 0,079 & 0,817 & $\begin{array}{l}\mathrm{C}=0,107 \mathrm{D}(\mathrm{P}<0,0001) \\
\mathrm{R}^{2}=0,49\end{array}$ \\
\hline
\end{tabular}

**significância do coeficiente angular ser igual a 1 (não haver diferença entre coberto e descoberto), pelo teste t.

TABELA 4 - Coeficientes de correlação (r) entre a dispersão anemófila de esporangiósporos de Plasmopara viticola e parâmetros micrometeorológicos em cultivo de videira (Vitis vinifera L.) cv. Moscato Giallo, com (coberto) e sem (descoberto) cobertura plástica, nos ciclos de 2005/06 e 2006/07. Flores da Cunha-RS.

\begin{tabular}{lcccccc}
\hline \multicolumn{1}{c}{$\begin{array}{c}\text { Dispersão de } \\
\text { esporangiósporos } \\
\text { Tratamento/Ciclo }\end{array}$} & $\begin{array}{c}\text { TempMáx } \\
\left({ }^{\circ} \mathrm{C}\right)\end{array}$ & $\begin{array}{c}\text { TempMín } \\
\left({ }^{\circ} \mathrm{C}\right)\end{array}$ & $\begin{array}{c}\text { TempMéd } \\
\left({ }^{\circ} \mathrm{C}\right)\end{array}$ & $\begin{array}{c}\text { UR } \\
(\%)\end{array}$ & $\begin{array}{c}\text { VV } \\
\left(\mathrm{m}_{\mathrm{s}^{-1}}\right)\end{array}$ & $\begin{array}{c}\mathrm{P} \\
(\mathrm{mm})\end{array}$ \\
\hline Coberto 2005/06 & $0,043 \mathrm{~ns}$ & $0,213 \mathrm{~ns}$ & $0,011 \mathrm{~ns}$ & $0,093 \mathrm{~ns}$ & $0,012 \mathrm{~ns}$ & $0,128 \mathrm{~ns}$ \\
Coberto 2006/07 & $-0,396^{* *}$ & $-0,530^{* *}$ & $-0,523^{* *}$ & $0,111 \mathrm{~ns}$ & $0,543^{* *}$ & $-0,010 \mathrm{~ns}$ \\
Coberto Total & $-0,428^{* *}$ & $-0,197$ & $-0,443^{* *}$ & $0,195 \mathrm{~ns}$ & $0,315^{* *}$ & $-0,027 \mathrm{~ns}$ \\
Descoberto 2005/06 & $0,259 \mathrm{~ns}$ & $0,409^{* *}$ & 0,254 & $0,173 \mathrm{~ns}$ & $0,468^{* *}$ & $0,456^{* *}$ \\
Descoberto 2006/07 & $-0,428^{* *}$ & $-0,478^{* *}$ & $-0,465^{* *}$ & $0,277 \mathrm{~ns}$ & $0,590^{* *}$ & $-0,106 \mathrm{~ns}$ \\
Descoberto total & $-0,151 \mathrm{~ns}$ & $-0,127 \mathrm{~ns}$ & $-0,189 \mathrm{~ns}$ & $0,151 \mathrm{~ns}$ & $0,214 \mathrm{~ns}$ & $0,093 \mathrm{~ns}$ \\
Total sistemas & $-0,340^{* *}$ & $-0,423^{* *}$ & $-0,486^{* *}$ & $0,329^{* *}$ & $0,113 \mathrm{~ns}$ & $-0,060 \mathrm{~ns}$ \\
\hline
\end{tabular}

TempMáx - temperatura máxima do ar próxima ao dossel; TempMín - temperatura mínima do ar próxima ao dossel; TempMéd - temperatura média do ar próxima ao dossel; UR - umidade relativa do ar próxima ao dossel; VV - velocidade do vento próxima ao dossel; PP - Precitação pluvial. ** - significativo a $1 \%$ de probabilidade, de acordo com teste $t$; ns - não significativo a $1 \%$ de probabilidade, de acordo com teste t. 


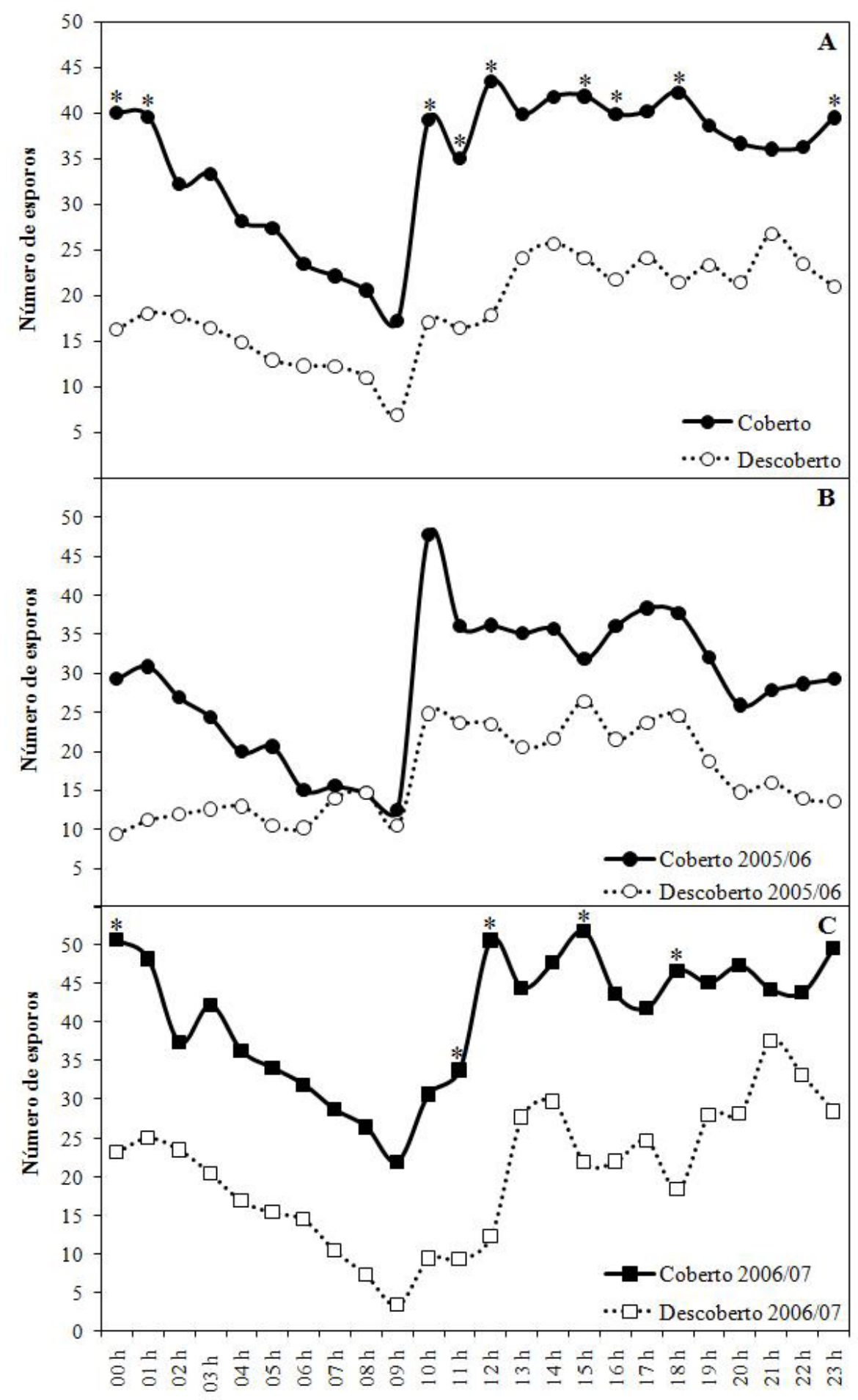

Horário (h)

FIGURA 1 - Dispersão de esporangiósporos de Plasmopara viticola em vinhedo (Vitis vinifera L.) da cultivar Moscato Giallo conduzida em "Y", com (coberto) e sem (descoberto) cobertura plástica. A - total dos ciclos de 2005/06 e 2006/07, B - ciclo de 2005/06 e C - 2006/07. Presença de asterisco representa diferença significativa, ao nível de $5 \%$ probabilidade de erro, de acordo com o teste de Tukey. 


\section{CONCLUSÕES}

1-O vinhedo sob cobertura plástica apresentou maior quantidade de esporangiósporos de Plasmopara viticola dispersos no ar.

2-Maiores dispersões anemófilas destes esporangiósporos foram observadas no período da tarde, independentemente do sistema de cultivo.

\section{REFERÊNCIAS}

AGRIOS, G.N. Plant Pathology. 4.ed. London: Academic Press, 1997. 635p.

AITA, L. Informações sobre a coleta de alguns fungos fitopatogênicos por amostragem do ar. Fitopatologia Brasileira, Brasília, v.8, p.377-379, 1983.

AlEXOPOUlOS, C.J.; MIMS, C.W.; BLACKWELL, M. Introductory mycology. 4. ed. New York: John Wiley \& Sons, 1996. 869p.

AMORIM, L.; KUNIYUKI, H. Doenças da videira. In: KIMATI, H.; AMORIM, L.; REZENDE; J.A.M.; BERGAMIN FILHO, A.; CAMARGO, L.E.A. (Ed.). Manual de fitopatologia: doenças das plantas cultivadas. 4.ed. São Paulo: Ceres, 2005. v.2, p.639-651.

CASA, R.T.; REIS, E.M.; ZAMBOLIM, L. Dispersão vertical e horizontal de conídios de Stenocarpella macrospora e Stenocarpella maydis. Fitopatologia Brasileira, Brasília, v.29, p.141-147, 2004.

CHAVARRIA, G.; SANTOS, H.P.; SÔNEGO, O.R.; MARODIN, G.A.B.; BERGAMASCHI, H.; CARDOSO, L.S.; SCHNEIDER, E.P. Cultivo protegido: uma alternativa na produção orgânica de videira. Revista Brasileira de Agroecologia, Porto Alegre, v.2, p.628 - 632, $2007 \mathrm{~b}$.

CHAVARRIA, G.; SANTOS, H.P.; SÔNEGO, O.R.; MARODIN, G.A.B.; BERGAMASCHI, H.; CARDOSO, L.S. Incidência de doenças e necessidade de controle em cultivo protegido de videira. Revista Brasileira de Fruticultura, Jaboticabal, v.29, n.3, p.477-482, 2007a.

CORREIA, M.S.; COSTA, J.L.S. Dispersão anemófila do fungo Lasiodiplodia theobromae em plantações de coqueiro. Fitopatologia Brasileira, Brasília, v.30, p.150-154, 2005.
DEAN, R.A. Regulations of gene expression and signals in fungal devlopment. In: VERMA, D.P.S. (Ed.). Molecular signal in plant-microbe communications. Boca Raton: CRS Press, 1992. p. 3-27.

FERREIRA, M.A.; PEDRO JÚNIOR, M.J.; SANTOS, A.O.; HERNANDES, J.L. Modificação parcial do cultivo da videira 'Cabernet Sauvignon' sobre diferentes porta-enxertos: Efeito sobre a produção e o teor de sólidos solúveis. Bragantia, Campinas, v.63, n.3, p.439-445, 2004.

FREIRE, L.M.M.; FREIRE, J.M.; CALDART, V.Z. Transformação na estrutura produtiva dos viticultores da Serra Gaúcha: 1985- 1991. Bento Gonçalves: EMBRAPA-CNPUV, 1992. 44p. (Documento, 7)

GRIGOLETTI JÚNIOR, A.; SÔNEGO, O. R. Principais doenças fúngicas da videira no Brasil. Bento Gonçalves: EMBRAPA-CNPUV, 1993. 36p. (Comunicado Técnico, 17)

MENDES, C.S. Flutuação de inóculo no ar, desenvolvimento e validação de um sistema de previsão do míldio-da-videira. 2002. 123 f. Dissertação (Mestrado) - Universidade de Passo Fundo, Passo Fundo, 2002.

ROSA, M.; GENESIO, R.; GOZZINI, B.; MARACHI, G.; ORLANDINI, S. Plasmo: a computer program for grapevine downy mildew development forecasting. Computers and Electronics in Agriculture, Amsterdan, v.9, p. 205-215, 1993.

SPENCER, D.M. The downy mildews. New York: Academic Press, 1981. 614p.

SUTTON, J.C. Predictive value of weather variables in the epidemiology and management on foliar diseases. Fitopatologia Brasileira, Brasília, v.12, p.305-311, 1998.

WONG, F.P.; WILCOX, W.F. Comparative physical modes of action of azoxystrobin, mancozeb, and metalaxyl against Plasmopara viticola (Grapevine Downy Mildew). Plant Disease, St Paul, v. 85, n. 6, p.649-656, 2001. 